\title{
Tumor initiation and progression in hepatocellular carcinoma: risk factors, classification, and therapeu- tic targets
}

\author{
Tamara SEVERI", Hannah van MALENSTEIN*, Chris VERSLYPE, Jos F van PELT* \\ Liver Research Facility \& Lab of Hepatology, University Hospital Gasthuisberg Leuven, Belgium
}

\begin{abstract}
Hepatocellular carcinoma (HCC) is a major health problem worldwide responsible for 500000 deaths annually. A number of risk factors are associated with either the induction of the disease or its progression; these include infection with hepatitis B or $\mathrm{C}$ virus, alcohol consumption, non-alcoholic steatohepatitis and certain congenital disorders. In around $80 \%$ of the cases, HCC is associated with cirrhosis or advanced fibrosis and with inflammation and oxidative stress. In this review we focus firstly on the different risk factors for $\mathrm{HCC}$ and summarize the mechanisms by which each is considered to contribute to HCC. In the second part we look at the molecular processes involved in cancer progression. HCC development is recognized as a multistep process that normally develops over many years. Over this period several mutations accumulate in the cell and that stimulate malign transformation, growth, and metastatic behavior. Over the recent years it has become evident that not only the tumor cell itself but also the tumor microenviroment plays a major role in the development of a tumor. There is a direct link between the role of inflammation and cirrhosis with this microenviroment. Both in vitro and in vivo it has been shown that tumor formation and metastatic properties are linked to epithelial-mesenchymal transition (EMT), a process by which facillitates the tumor cell's attempts to migrate to a more favourable microenviroment. Several groups have analyzed the gene expression in HCC and its surrounding tissue by microarray and this has resulted in the molecular classification into a distinct number of classes. Here we also found a role for hypoxia induced gene expression leading to a clinically more aggressive gene expression in HCC. Molecular analysis also helped to identify important cellular pathways and possible therapeutic targets. The first molecule that in this way has shown clinical application for liver cancer is the multikinase inhibitor sorafenib, others are currently in different stages of clinical studies like the mTOR inhibitor everolimus.
\end{abstract}

Keywords: liver cancer; hypoxia; prognosis; targeted therapy; molecular classification

Acta Pharmacologica Sinica (2010) 31: 1409-1420; doi: 10.1038/aps.2010.142; published online 18 Oct 2010

\section{Hepatocellular carcinoma}

Hepatocellular carcinoma (HCC) is a malignant tumour arising from the hepatocytes. HCC represents a major health problem. Worldwide, it ranks fifth among the solid tumours and it is the third cause of cancer-related mortality in males with $\sim 500000$ deaths each year ${ }^{[1]}$. It is most prevalent in Asia (the annual incidence in China equals 100 per 100000 ) and Africa. In Africa, HCC is mostly related to chronic hepatitis $B$ virus (HBV) infection, in Asia to hepatitis B or C. The incidence in Europe and the USA is considerably lower with an annual incidence between $1-10$ per 100000 , but it is rising mainly due to hepatitis $\mathrm{C}(\mathrm{HCV})$ virus infection with an expected fivefold increase peaking around $2015^{[2]}$. In more

\footnotetext{
\# Both autors contributed equally to this manuscript.

* To whom correspondence should be addressed.

E-mail Jos.vanPelt@med.kuleuven.be

Received 2010-06-13 Accepted 2010-07-22
}

than $80 \%$ of cases, HCC is associated with cirrhosis or with advanced fibrosis ${ }^{[3,4]}$. Cirrhosis is mostly due to chronic infection with the HBV or HCV, alcohol abuse, or metabolic disorders like hemochromatosis. More recently, non-alcoholic steatohepatitis (NASH) resulting from the insulin resistance syndrome is emerging as another important risk factor for cirrhosis and $\mathrm{HCC}^{[5]}$. The major risk factors for the development of HCC are summarized in Table 1.

\section{Inflammation, chronic liver disease and cancer}

Inflammation occurs in livers that are exposed to a wide variety of substances (hepatitis viruses, intermediates of alcohol metabolism, drugs etc) ${ }^{[7]}$. When the hepatic metabolism fails to convert drugs to non-reactive or non-immunogenic substances, the intermediates may damage hepatocytes or trigger Kupffer and other cells to release inflammatory cytokines and mediators. Viral proteins may also elicit an immune reaction, which can be equally detrimental for the intruder, the infected 
Table 1. Risk factors for HCC. Known risk factors associated with hepatocellular carcinoma (Adapted from Bosch et al, Gastroenterology $2004^{[6]}$ )

$\begin{array}{ll}\text { Major risk factors for HCC are: } \\ 80 \% & \text { Cirrhosis or advanced fibrosis, mostly due to } \\ & \text { - Hepatitis B virus infection } \\ & \text { - Hepatitis C virus infection } \\ & - \text { Alcohol } \\ & \text { - NASH } \\ & \text { - Congenital disorders such as Hemochromatosis, } \\ & \text { Wilson's disease, etc. }\end{array}$

$20 \%$

In the absence of Cirrhosis or advanced fibrosis
- Hepatitis B virus infection
- Aflatoxin (mostly combined with HBV)
- Some genetic disorders such as Tyrosinosis
- Drug induced (eg anabolic steroids)

cell and the surrounding hepatocytes ${ }^{[8]}$. During the metabolisation of offending drugs or during immunological reactions, reactive oxygen species (ROS) are generated and this oxidative stress plays a central role in causing tissue damage, which will be discussed further ${ }^{[0]}$.

A variety of cells cooperate in inflammatory reactions. Indeed, the liver lobule is formed by hepatocytes, cholangiocytes and non-parenchymal cells (Kupffer cells, sinusoidal endothelial cells and hepatic stellate cells (HSC). In addition, intrahepatic lymphocytes and liver-specific natural killer cells are present in the sinusoidal lumen and in the perisinusoidal space of Disse. Toxic substances as well as immunological responses per se can initiate a process of necrosis and stimulate inflammation through activation of Kupffer and HSC. The HSC will acquire a myofibroblastic phenotype in the various types of liver disease and this process can lead to liver fibrosis through the excess deposition of extracellular matrix. This deposition of extracellular matrix often results in reduction of the blood flow in parts of the liver ${ }^{[10,11]}$. Fibrosis can develop into cirrhosis, which is responsible for significant morbidity and mortality and is one of the most important risk factors for the development of HCC. During cirrhosis irreversible, architectural changes occur with nodule formation, whereby hepatocytes lose their normal two-cell plate-like arrangement ${ }^{[12]}$.

Cirrhosis is associated with the development of HCC, but the molecular basis for the cancer-promoting effect of cirrhosis remains far from clear. There is accumulating evidence in favor of a dysplasia-carcinoma sequence as has been identified in other types of cancer such as in colon carcinoma. It is hypothesized that the process of recurrent liver cell necrosis and regeneration with increased cell turn-over, renders liver cells more sensitive to the adverse effects of other mutagenic agents. Both genetic and epigenetic changes may occur, eventually leading to the subsequent formation of dysplastic foci, nodules and finally hepatocellular carcinoma ${ }^{[13,14]}$.

Certain mutagenic factors are associated with a specific genetic signature (such as aflatoxin), while other genetic changes across different etiologies are identified ${ }^{[15]}$.

From an epidemiological and clinical point of view HBV, $\mathrm{HCV}$ and alcoholic cirrhosis are clearly the most important diseases for the development of HCC. From a pathophysiological perspective, oxidative stress represents an important pathway by which viruses or others risk factors exert their carcinogenic properties. Both hepatitis viruses and oxidative stress will be described in more detail in this review.

\section{Hepatitis B virus}

In adults, HBV infection mostly results in acute (rarely fulminant) hepatitis; in $10 \%$, this infection will evolve to chronic hepatitis that can ultimately lead to the development of cirrhosis and eventually to hepatocellular carcinoma. In neonates or young children, the infection may run an asymptomatic chronic course, but this state of persistent HBV infection can also lead to the development of $\mathrm{HCC}^{[16]}$. Worldwide, more than 350 million individuals are infected with HBV and it is estimated that each year 1 million people die because of infection with this virus ${ }^{[17]}$.

HBV belongs to the Hepadnaviridae, whose members can infect only certain species, being man or a specific animal such as chimpanzee, woodchuck, ground squirrel or duck. All hepadnaviridae display structural homology, infect primarily the liver and can cause hepatitis; chronic infection with (mammalian) hepadnaviridae can result in development of $\mathrm{HCC}^{[18]}$.

HBV has a circular, partially double-stranded, DNA genome, consisting of four major, partially overlapping open-reading frames that encode for 4 completely different proteins: surface (S, PreS1, PreS2), Precore/C, DNA polymerase (P), and the $\mathrm{X}$ protein. The surface proteins ( $\mathrm{S}, \mathrm{PreS1}$, and PreS2) are expressed on the surface of the infectious virion, or on "empty" particles present in the serum which are highly immunogenic $^{[19]}$. The core protein has a structural function and may play an important role in the viral life cycle. The DNA polymerase gene product is a multifunctional protein that contains a primase or terminal protein, a spacer, DNA polymerase/ reverse transcriptase and RNase. The P protein is the sole viral protein required for the correct priming of reverse transcription. The $\mathrm{X}$ gene encodes a basic protein that is a transcriptional trans-activator and can upregulate the activity of the HBV genome ${ }^{[20]}$. HBx also influences the expression of a number of host genes, especially genes involved in cell survival, cell cycle progression and invasion ${ }^{[21-23]}$.

The link between HBV and HCC may be related to the inflammatory response to HBV infection and/or a direct role of the above mentioned gene products of HBV. The immune response to $\mathrm{HBV}$-encoded antigens is responsible both for viral clearance and for disease pathogenesis. While the humoral antibody response to viral envelope antigens contributes to the clearance of circulating virus particles, the cellular immune response to the envelope, nucleocapsid, and polymerase antigens eliminates infected cells. The class I- and class II-restricted $\mathrm{T}$ cell responses to the virus are vigorous, polyclonal, and multispecific in acutely infected patients who successfully clear the virus, while the responses are weak and 
more narrowly targeted in chronically infected patients ${ }^{[24]}$.

The pathogenetic and antiviral potential of the cytotoxic $\mathrm{T}$ lymphocyte (CTL) response to HBV has been demonstrated by the induction of a severe necro-inflammatory liver disease following the adoptive transfer of HBsAg-specific CTL into HBV transgenic mice, and by the non-cytolytic suppression of viral gene expression and replication in the same animals by a post-transcriptional mechanism mediated by interferon gamma, tumour necrosis factor alpha, and interleukin $2^{[20]}$. The dominant cause of viral persistence during HBV infection is the development of a weak antiviral immune response to the viral antigens. While neonatal tolerance and juvenile partial tolerance seems to play an important role in viral persistence in patients infected at birth or before age 5 year, the basis for poor responsiveness in adult-onset infection is not well understood and requires further study. Some HLA types seem protective against chronic HBV infection ${ }^{[25,26]}$.

$\mathrm{HBV}$ can integrate integrate in the host genome where it can promote malignant transformation. HBV integration can cause microdeletions in the host DNA on positions that may involve cancer relevant genes such as MAPK and TERT ${ }^{[27]}$. HBV can also persist in the liver for many years in the socalled cccDNA form, the intermediate form required for viral reproduction $^{[28]}$. Through this mechanism, there will be a continous immunological respons on newly produced viral antigens in these chronically infected patients that can contribute to cellular damage and malignant transformation (see also oxidative stress). Data related to the influence of different hepatitis $B$ virus genotypes and the emergence of selective variants as biomarkers of HCC development still remain controversial. Recent studies on occult HBV infection, as defined by serologically undetectable hepatitis B surface antigen (HBsAg-) despite the presence of circulating HBV DNA, suggest that the occult viral strains, maintaining the transcriptional activity and the pro-oncogenetic assets of the clear HBV infection (HBsAg+), may harbour a potential risk for liver cancer development ${ }^{[29]}$.

Concerning the gene products of $\mathrm{HBV}$, there is a central role for the HBV $X$ gene. HBx is a transcriptional factor that regulates gene expression of several oncogenes ${ }^{[30,31]}$ and its carcinogenic potential was demonstrated in transgenic mice who developed HCC in $90 \%$ of the cases ${ }^{[32]}$. HBx has been shown to directly impair insulin signaling which suggest some common mechanism between HBV induced HCC and in fatty liver disease/NASH/NAFLD ${ }^{[33]}$.

Also, the preS2/S protein of HBV is linked to HCC development via activation of hTERT and so to $\mathrm{HCC}^{[34]}$.

Chronic liver cell injury and the inflammatory and regenerative responses are believed to create the mutagenic and mitogenic stimuli leading to HCC.

\section{Hepatitis $\mathbf{C}$ virus}

Hepatitis C virus infection (HCV) is currently the most common cause of chronic liver disease in the USA, Australia, Japan and Western Europe. As the infection is usually acquired in adult life through the parenteral route and because progression of chronic hepatitis over cirrhosis to cancer can take sev- eral decades, most patients are of late middle or old age when they are diagnosed with $\mathrm{HCC}^{[35]}$. However, $\mathrm{HCV}$ is associated with a higher risk to induce chronic infection $(60 \%-80 \%$ vs $10 \%$ in $\mathrm{HBV}$ ) and therefore with HCC development as well compared to $\mathrm{HBV}^{[36]}$.

The rate of fibrosis progression is highly variable, and is influenced by the amount of alcohol consumption, age at the time of HCV infection, degree of inflammation and co-infection with HIV or HBV. HCC occurs in approximately $2 \%$ of cirrhotic patients per year.

The HCV is a single-stranded positive-sense RNA virus of $9400 \mathrm{bp}$. The HCV genome contains a single large openreading frame encoding a polyprotein precursor of 3010-3033 amino acids, depending on the viral isolate. HCV structural genes (core and envelope) are encoded at the $5^{\prime}$ region of the genome. Non-structural genes occupy the remaining two-thirds of the $3^{\prime}$ region of the viral genome. Non-coding regions of the virus are crucial to viral replication and are found at both ends of the genome ${ }^{[37]}$.

The life cycle of HCV is confined to the cytoplasm of the host cell. The viral genome does not integrate into the host cell genome and does not express a reverse transcriptase as HBV does. Therefore its role in carcinogenesis has generally been assumed to be mediated by the chronic necro-inflammatory process. Negative replicative and positive genomic strands of the virus are present in both liver and tumour tissue; this indicates that HCV not only infects hepatocytes but also replicates in them during, and possibly even following malignant transformation $^{[37]}$. In addition to necro-inflammatory processes, direct effects of viral proteins on the host cell can also play a role in the malignant transformation of the hepatocytes to $\mathrm{HCC}$.

The HCV core protein seems to be involved in overcoming apoptosis since it interferes with for example TNFa signaling $^{[38]}$. HCV core protein in particular also can induce insulin resistance and this might further trigger development of $\mathrm{HCC}^{[39,40]}$. A link with insulin has also been found for HBV (see above). Liver cancer-derived hepatitis $\mathrm{C}$ virus core proteins shift TGF-beta responses from tumor suppression to epithelial-mesenchymal transition which is discussed below ${ }^{[41]}$.

Mutations in the hepatitis $C$ virus core gene are associated with advanced liver disease and hepatocellular carcinoma ${ }^{[42]}$. And there has been found an association between mutations in the core region of hepatitis $C$ virus genotype 1 and hepatocellular carcinoma development ${ }^{[43]}$.

Non-structural 5A protein of hepatitis $C$ virus induces a range of liver pathology in transgenic mice ${ }^{[44]}$ and Hepatitis $C$ virus NS5A protein is shown to interacts with beta-catenin and stimulates its transcriptional activity in a phosphoinositide-3 kinase-dependent fashion ${ }^{[45]}$.

Hepatocellular carcinoma displays distinct DNA methylation signatures ${ }^{[46,47]}$, including genes inhibitory to cancerrelated signaling such as RAS/RAF/ERK and Wnt/betacatenin pathways. Also, in a group of patients the methylation of dual specificity phosphatase 4 (DUSP4), cytochrome P450, family 24, subfamily A, polypeptide 1 (CYP24A1), and 
natriuretic peptide receptor A (NPR1) correlated significantly with recurrence-free survival. Deng et al concluded that DNA methylation might play an important role in HCV-related HCC by silencing cancer-related pathway inhibitors ${ }^{[47]}$.

\section{Alcohol, steatohepatitis, and related fatty liver diseases}

Fatty liver disease is a heterogeneous condition characterized by fatty degenerative changes of hepatocytes, induced by alcohol, insulin resistance or metabolic diseases. In the clinic fatty liver disease is commonly divided into two conditions: alcoholic and non-alcoholic fatty liver disease (NAFLD) ${ }^{[48]}$.

The histology of fatty liver diseases extends from steatosis to steatohepatitis, fibrosis and cirrhosis. Alcoholic or nonalcoholic steatohepatitis (ASH or NASH) is characterized by the accumulation of fat droplets in the cytoplasm of hepatocytes and the additional presence of various degrees of lobular inflammation, hepatocyte-ballooning, -apoptosis, and -necrosis, and fibrosis. In obese persons, the prevalence of NAFLD reaches as much as $75 \%$ to $90 \%{ }^{[49]}$.

The principal risk factors for NAFLD are visceral obesity, type 2 diabetes mellitus, hypertension and hyperlipidemia.

Several mechanisms have been proposed to explain carcinogenesis in $(\mathrm{N}) \mathrm{ASH}^{[50-55]}$. But in both cases inflammation and the generation of reactive oxygen species play a pivotal role. Chronic alcohol abuse leads to multiple biochemical changes that could indirectly initiate or potentiate liver cancer. Alcohol is metabolized to acetaldehyde by alcohol dehydrogenase and by cytochrome P450 2E1 (CYP2E1). Both steps lead to the production of $\mathrm{NADH}$, which can lead to oxidative stress and gluthatione depletion. This will be explained in more detail later. Furthermore, acetaldehyde is considered as a carcinogen in animal studies. In addition, animal studies have shown that the production of S-adenosylmethionine (SAM), the methyl donor for DNA methylation reactions, is decreased in alcoholinduced cirrhosis. Because DNA methylation is an important regulator of gene expression, epigenetic abnormalities in DNA methylation in alcohol-induced cirrhosis could also contribute to changes in gene expression and the development of $\mathrm{HCC}^{[56]}$.

\section{Oxidative stress and HCC}

Oxidative stress is caused by an imbalance between on one hand, the production of ROS and reactive nitrogen species (RNS) and on the other hand, the ability to detoxify these reactive intermediates or to easily repair the resulting damage. All forms of life maintain a reducing environment within their cells. The cellular redox environment is preserved by enzymes that can maintain this reduced state through a constant input of metabolic energy. Disturbances in the normal redox state can have toxic effects by overproduction of peroxides and free radicals.

In humans, oxidative stress is thought to be involved in many diseases, such as atherosclerosis, liver disease, Parkinson's disease, Alzheimer's disease and ageing ${ }^{[57,58]}$. However, reactive oxygen species can also be beneficial, as they are used by the immune system as a way to attack and kill pathogens and by the cell as signaling molecules.
In case of liver disease, ROS and RNS seem to play a crucial role in the pathogenesis and the progression of HCC irrespective of the etiology. ROS and RNS are involved in the transcription and activation of a large series of cytokines and growth factors, which in turn, can contribute to further production of ROS and RNS. Hepatocyte mitochondria and cytochrome P450 enzymes, endotoxin-activated macrophages (Kupffer cells) and neutrophiles represent the main sources of free radicals. These free radicals will alter the redox state, and the cellular tissue damage may be potentiated by an associated decrease of antioxidant and energetic reserves. These radicals have a short half-life but they can react with many classes of molecules or compounds (proteins, membranes, DNA and RNA) $)^{[59]}$.

To counteract the effect of oxidative stress, cells have developed two important defense mechanisms: redox active sulfhydryl systems [glutathione (GSH) and thioredoxine (TRX) and enzymatic systems (including superoxide dismutase, catalase and glutathione peroxidase) $]^{[60]}$. Glutathione is the most abundant non-protein sulfhydryl-containing compound in the cell and constitutes the major thiol buffer.

There is considerable evidence that redox signaling mechanisms function in cell regulation and growth control. Not only is cellular GSH involved in proliferation, changes in the cellular GSH/Glutathione disulfide (GSSG) redox state (oxidative stress) have been implicated in cell cycle responses such as differentiation and apoptosis ${ }^{[6] 1}$. The redox status of the cells can be calculated by the Nernst equation for the couple GSSG/2GSH. Another marker for oxidative stress is malondialdehyde (MDA) that is formed during lipid peroxidation and was shown to accumulate in serum of chronic hepatitis patients ${ }^{[2]}$. An imbalance in the redox homeostasis results in an increased flux of reactive oxygen species ${ }^{[63]}$. Under such pro-oxidant conditions, highly reactive radicals can damage DNA, RNA, proteins and lipid components, and this may lead to mutations or apoptosis ${ }^{[61,64]}$.

Eukaryotic cells possess evolutionary conserved mechanisms to accurately and efficiently repair the majority of DNA damage, thereby ensuring genomic integrity. Important repair pathways include base excision repair, nucleotide excision repair, mismatch repair, non-homologous end joining and homologous recombination. Defects or reduction in DNA repair processes generally result in susceptibility to cancer. Both hepatitis B virus and oxidative stress itself have been shown to interfere with DNA repair and may increase de novo HBV DNA integration ${ }^{[65,66]}$.

\section{Hepatocarcinogenesis and tumormicroenviroment}

Hepatocarcinogenesis is a multistep process in which a number of mutational genetic alterations accumulate in a cell (Figure 1). It involves the transition of a normal cell via the so called initiated cell to a preneoplastic lesion that develops into malignant tumour and to clinical liver cancer ${ }^{[67]}$.

Hepatocytes in normal adult liver hardly ever proliferate and have a life span of over a year. After extensive liver damage or in situations where hepatocyte regeneration after dam- 


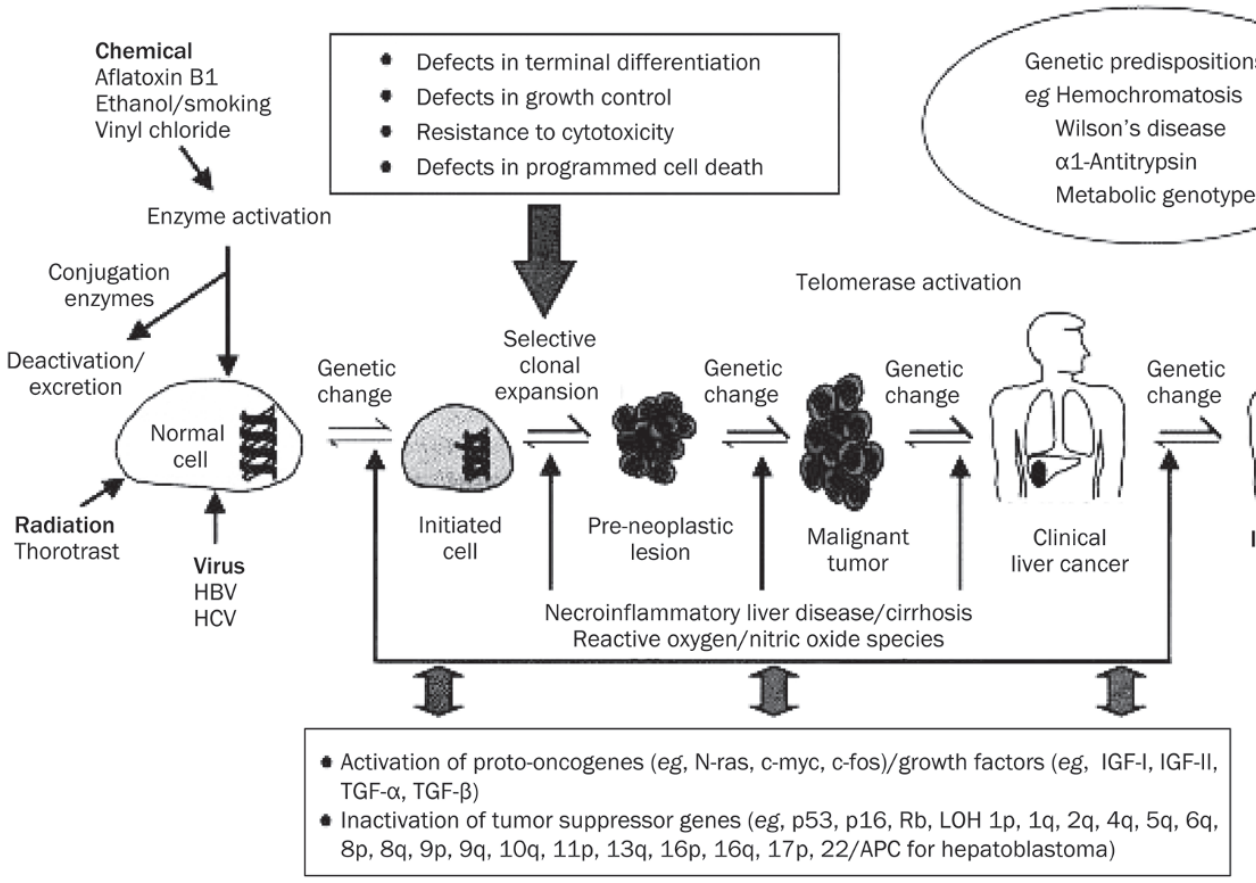

Figure 1. Schematic representation of the multistep process of hepatocarcinogenesis (from Wang et al, Toxicology $2002^{[68]}$ with permission). age is compromised, proliferation of a (facultative) stem cell compartment is observed, consisting of the hepatic progenitor cells (HPC) located in the canals of Hering near the smallest branches of the biliary tree. These cells are bipotential and capable of differentiating into either hepatocytes or cholangiocytes. These HPC's are small cells with a large nucleus and a narrow rim of cytoplasm, in animals also called oval cells. The degree of this progenitor cell activation is positively correlated with the inflammatory activity and the stage of the disease. Recently, it has been shown that in the cirrhotic stage of most chronic liver diseases, the hepatocytes become senescent owing to telomere shortening. Some senescent cells acquire additional mutations and an associated gain in replicative capacity this makes it even more plausible that at least part of the hepatocellular carcinomas originate from a progenitor cell.

Using immunohistochemistry (OV-6 and GST-P) and RNAFISH (HGF, EGF, CK19, and H19) identified isolated stem cells scattered in the liver parenchyma of cirrhotic livers and within hepatocellular carcinomas (HCCs). Precirrhotic ASH or NASH all stained negative for these stem cells. In HCCs, 13 out of 15 had stem cells located within the tumor (78\%). In cirrhotic livers, 12 out of $28(37 \%)$ had liver parenchymal stem cells present ${ }^{[69]}$.

Several studies suggest that HCC with stem cell features have a poor prognosis. Lee et al showed significant survival differences between HCC patients with a hepatocyte-like phenotype and a hepatoblast-like phenotype ${ }^{[70,71]}$. Other studies suggest that HCC positive for Keratin 19 (KRT19), which is a progenitor cell marker, have a higher rate of recurrence after resection or transplantation ${ }^{[72-74]}$. Other fetal markers such as AFP and epithelial cell adhesion molecule (EpCAM) are of prognostic value as well, since EpCAM+/AFP+HCC is associated with poor survival ${ }^{[75]}$.
Supported by a growing number of scientific reports it has become clear over recent years that also the tumor enviroment plays an important role in tumorigenesis and tumor progression $^{[76]}$. Cancer cells are not as autonomous as once thought, they depend on angiogenesis, inflammatory cells and fibroblasts ${ }^{[77,78]}$. Obvious, in the cirrhotic liver there is an abundancy of fibroblasts and there is emerging evidence that some are cancer associated fibroblasts $(\mathrm{CAFs})^{[79]}$. In HCC, the progression of malignant hepatocytes frequently depends on transforming growth factor (TGF)-beta provided by the stromal cells (fibroblasts, macrophages etc). This TGF-beta is one of the factors that can induce an Epithelial-to-Mesenchymal Transition (EMT) ${ }^{[80]}$. For different types of tumors it has been demonstrated that an EMT-switch is associated with a worse prognosis as seen in esophageal squamous cell carcinoom $^{[81]}$, gastric cancer cells ${ }^{[82]}$ bladder cancer ${ }^{[83]}$ non-small cell lung cancer ${ }^{[84]}$ and pancreas ductal adenomacarcinoma ${ }^{[85]}$. For HCC, this correlation has also been found with an independent effect of Twist and Snail in promoting metastasis of hepatocellular carcinoma ${ }^{[86-89]}$.

Characteristics for EMT are a shift in gene expression with an upregulation of Twist ${ }^{[85,90]}$, Snail ${ }^{[91]}$, VE-cadherin ${ }^{[92]}$, Vimentin $^{[93]}$, downregulation of E-cadherin ${ }^{[94]}$, hepatocyte transcriptional factor HNF4alpha and changes in the cytoskeleton. Important molecular pathway involved in EMT are Wnt/betacatenin signaling ${ }^{[95,96]}$ and through growth factor signalling like PDGF ${ }^{[97]}$.

In EMT there is a de-stabilization of adherent junctions ${ }^{[98]}$ and the cells develop more invasive properties ${ }^{[93]}$.

In mouse models, both in vitro and in vivo, epithelial-tomesenchymal transition has been shown to promote invasion and metastasis ${ }^{[99,100]}$.

Both hepatitis B virus ${ }^{[101]}$ and hepatitis $C$ virus $^{[102]}$ are fac- 
tors that contribute to EMT in HCC tumor progression. The tumormicroenviroments is also influenced by hypoxia through Hif1a ${ }^{[103]}$ and hypoxia might stimulate EMT ${ }^{[104]}$.

Kim et al has shown that epithelial-to-mesenchymal transition gene signature can predict clinical outcome of hepatocellular carcinoma. They used RT-PCR to determine expression of EMT-related genes and could predict survival of patients using only four genes (E-cadehrin (CDH1), inhibitor of DNA binding 2 (ID2), matrix metaloproteinase 9 (MMP9), and transcription factor 3 (TCF3 $)^{[105]}$. Both this gene signature and the hypoxia signature (discussed below) are candidates to be included in a more comprehensive molecular classification of HCC and could supply us with valuable therapeutic targets.

\section{Molecular classification}

Several studies have tried to classify HCC based on their gene expression or on their chromosomal alteration. Obtaining a molecular classification of hepatocellular carcinoma, however, remains a striking challenge because of the overwhelming genomic complexity of $\mathrm{HCC}^{[106]}$. Hitherto, there are three large studies published that classify HCC based on gene expression. Two of them could identify subgroups with common affected pathways such as beta-catenin and proliferation signals ${ }^{[107,108]}$ and one group ${ }^{[70,109]}$ was able to correlate the subgroups with survival. Other studies tried to find common affected genes that are associated with prognostic factors such as vascular invasion and metastasis, but the overlap between these studies is very poor. Two groups studied the surrounding liver tissue, instead of the tumor tissue itself. Based on these findings late recurrence can be predicted in cirrhotic patients, since these recurrences are probably "second primary tumors in an at-risk liver". Table 2 summarizes some of the most important studies regarding the molecular classifications of hepatocellular carcinoma.

These studies led to the transcriptome classification as developed by Zucman-Rossi and Boyault (Figure 2).
A subgroup of patients have activation of pathways related to cell proliferation (IGF signaling, RAS/MAPK, and mTOR signaling), and differentiation (Wnt- $\beta$-catenin and Hedgehog). Overall we can classify as follows: 1) a proliferation subgroup with Akt/mTOR activation, 2) the closely related DNArepair/Cell-cycle subgroup, 3) the Beta-catenin subgroup, 4) the immune related subgroup, 5) the MAPK/cjun/c-Myc related genes and Jak/STAT related genes and 6) the metastasis related genes group. The prognostic implication of this clustering based on pathways remains unclear.

\section{Hypoxia and tumor progression}

The role of hypoxia in initiation and progression of HCC is only partly understood. Hypoxia is involved in neo-angiogenesis and the formation of new blood vessels, induction of gene expression through the transcription factor Hif1a that regulates more than 50 targets genes and also hypoxia stimulates EMT in $\mathrm{HCC}^{[120]}$ involving PI3 kinase/ AKT signaling ${ }^{[121-123]}$.

From our own recent studies it has come forward that hypoxia has an additional role. Central in our study was the working hypothesis that chronic exposure to hypoxia leads to an adaptive gene expression profile which influences the aggressive behavior of the tumor cells. To test our hypothesis independently of patient selection and variability, we decided to start from cell culture. We determined the gene expression pattern for human HepG2 liver cells under chronic hypoxia by microarray. Differentially expressed genes were selected and their clinical value was assessed. In our hypothesisdriven analysis we included available independent microarray studies of patients with HCC in one single analysis. Three microarray studies were used as training sets to determine a minimal prognostic gene set and one additional study was used for validation. Using computational methods we identified 7 genes, out of 3592 differentially expressed under chronic hypoxia, that showed correlation with poor prognostic indicators in all training sets (272 patients) and this was validated

\section{HCC transcriptome classification}

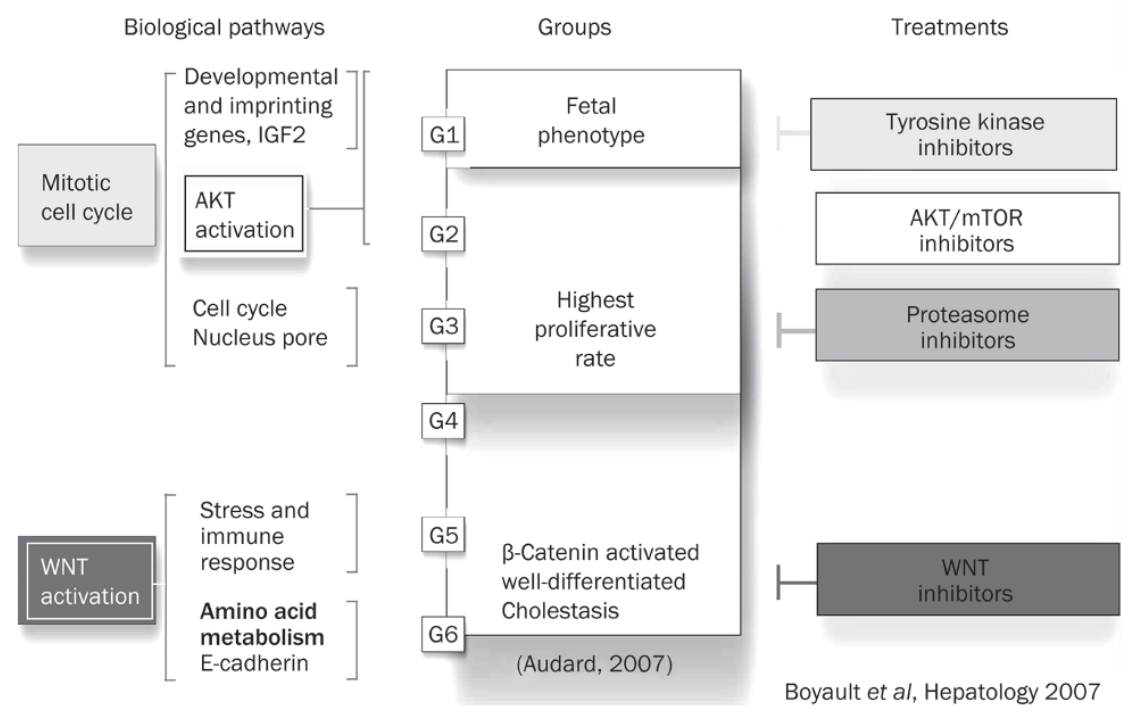

Figure 2. Transcriptome classification of HCC. HCC were divided into six groups with their main biological and molecular features and their implications for the selection of targeted therapies (after ZucmanRossi et al ${ }^{[107]}$ with modifications ${ }^{[119]}$. 
Table 2. Overview of different studies on HCC in which microarray technique were used.

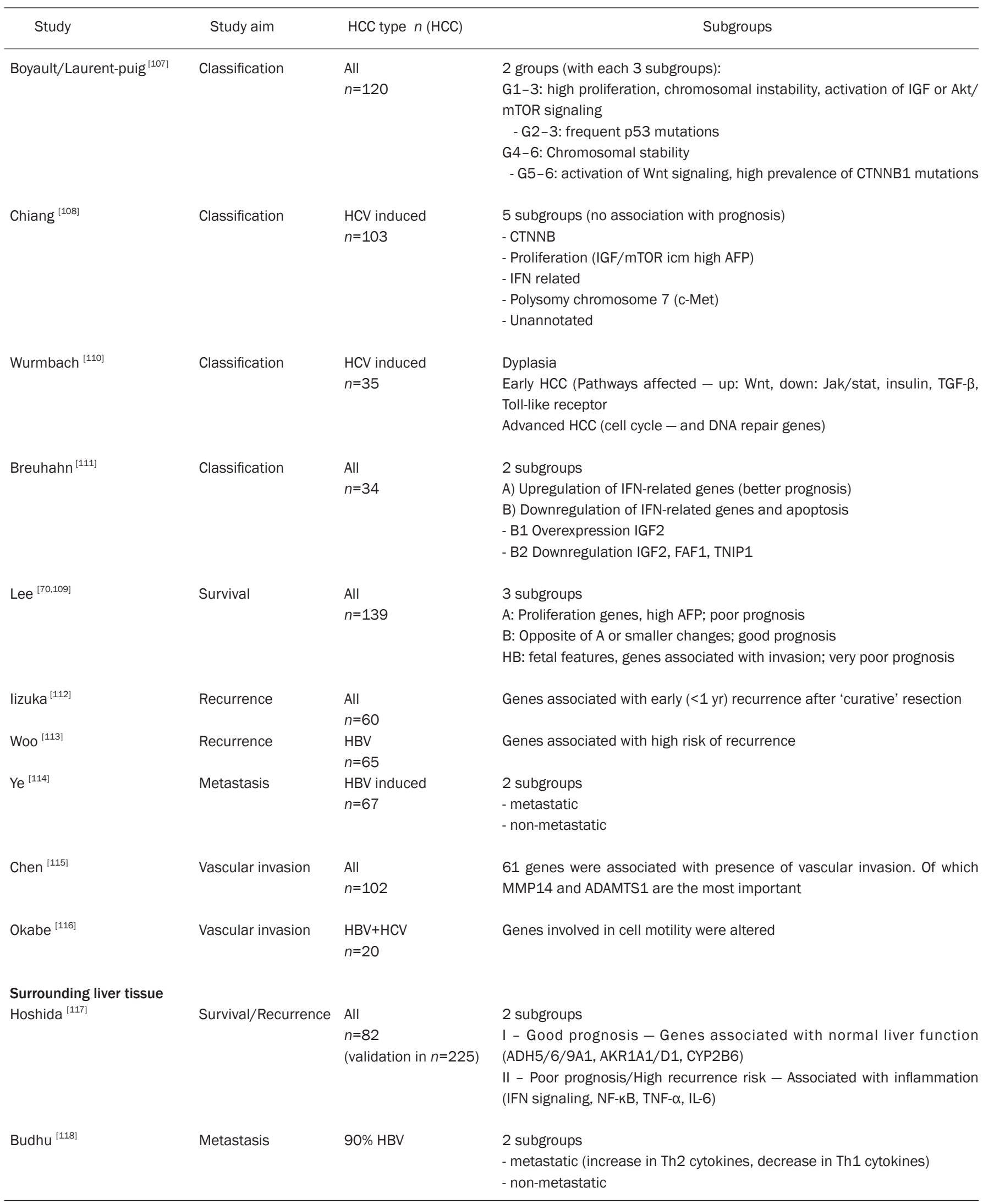


in a 4th dataset (91 patients). Retrospectively the 7-gene set is associated with poor survival (HR 1.39, $P=0.007$ ) and early recurrence (HR 2.92, $P=0.007$ ) in 135 patients. Moreover, using a hypoxia score based on this 7 -gene set we found that patients with a score $>0.35$ had a median survival of 307 days, whereas patients with a score $\leq 0.35$ had a median survival of 1602 days $(P=0.005)^{[124]}$.

These findings may have prognostic implications for HCC patients and therefore could be incorporated in the molecular classification of HCC. Furthermore, we suggest that gene expression under chronic hypoxia might lead to new therapeutic targets and the hypothesis-driven experimental methods we used can be applied to other malignancies as well.

\section{Therapeutic targets}

Dysregulation of pleiotropic growth factors, receptors and their downstream signaling pathway components represent a central pro-tumourigenic principle in human hepatocarcinogenesis.

Especially the Insulin-like Growth Factor/IGF-1 receptor (IGF/IGF-1R), Hepatocyte Growth Factor (HGF/MET), Wingless (Wnt/beta-catenin/FZD), Transforming Growth Factor alpha/Epidermal Growth Factor receptor (TGFalpha/EGFR) and Transforming Growth Factor beta (TGFbeta/TGFbetaR) pathways contribute to proliferation, anti-apoptosis and invasive behavior of tumour cells. Resultant functional effects are modulated by multiple cross-talks between the different signaling pathways and additional tumour-relevant factors, such as cyclooxygenase- 2 and p53. With the identification of relevant pathways, specific therapeutic strategies can be developed. Some of these malignant signaling pathways have been identified and have been studied to develop new therapies ${ }^{[106,125,126]}$.

\section{Treatment}

Treatment of patients with HCC is based on staging, which includes assessment of tumour extent, liver function, portal pressure and clinical performance status. The widely used Barcelona-Clinic-Liver-Cancer (BCLC) staging system links staging of HCC in cirrhosis with treatment modalities ${ }^{[127,128]}$. The system identifies those patients with early HCC (stage 0 and A) who may benefit form curative therapies (resection, radiofrequency ablation, liver transplantation), those at intermediate or advanced stage (stage B, C) who may benefit from palliative treatments (such as transarterial chemo- or radioembolisation), and the patients with a very poor life expectancy (stage D) where best supportive care is the only option ${ }^{[129]}$.

Until recently, patients with advanced hepatocellular carcinoma (BCLC-stage C) could only be offered best supportive care or systemic chemotherapy with an unfavourable riskbenefit ratio. The advent of targeted drugs has offered hope to our patients. Sorafenib is a multikinase inhibitor targeting the Raf serine/threonine kinases and the VEGFR1-3, PDGFR- $\beta$, c-Kit, Flt3, and p38 tyrosine kinases, that block the VEGF and PDGF-dependent angiogenesis. The drug is now considered the standard of care in patients with advanced hepatocel- lular carcinoma and preserved liver function, based upon two phase III trials that showed an improved overall survival and progression free survival compared to placebo. Median survival increased from 7.9 to 10.7 months (hazard ratio 0.69, $95 \%$ CI $0.55-0.87)^{[130,131]}$. Most drug-related and manageable adverse events include fatigue, anorexia, diarrhea and handfoot skin reaction. Unfortunately, all patients with advanced HCC still die from the disease and there is an unmet need for other drugs, either as a single agent or in combination with sorafenib. A phase III clinical trial with sunitinib, a drug with a similar mode of action as sorafanib, has recently been stopped because of higher toxicity and no superior efficacy compared to sorafenib. Other clinical trials explore the safety and efficacy of everolimus that targets mTOR, which is a central regulator of cell growth and angiogenesis.

So far, the molecular classification of HCC has not yet found its place in the staging systems and selection of therapy. However, the active search and analysis for biomarkers in all current phase III studies may rapidly change the field.

\section{Conclusions and perspectives}

As pointed out in this review, HCC is a complex disease which can have different etiological origin. The disease is further complicated because it usually requires multiple hits (mutations), develops over many years and its clinical diagnosis is often at an advanced stage. The driving molecular mechanisms are under study and several groups have worked at the development of molecular classification systems, which provide road maps for the identification of therapeutic targets. Our studies on the role of hypoxia as a factor inducing a more aggressive gene expression profile, yielded an additional pathway attractive for therapeutic intervention. So far, treatment has been based on clinical staging systems. With the increasing knowledge of the biology of HCC a rational, individualized approach will become possible for the treatment of patients. In the future the models for molecular classification will further merge with the current staging and treatment algorithms. The discovery of sorafenib as an active and safe drug for patients with advanced HCC serves as a proof of principle clearly boosted the field and offers hope for the patients and the oncologic community.

\section{Acknowledgements}

We thank Prof Dr em J FEVERY for valuable discussions during the preparation of the manuscript. We also want to thank the technicians Mr M ZEEGERS, Mrs P WINDMOLDERS, and Mrs I VANDERELST for their contributions to the experimental liver research at our laboratory.

HvM is research assistant of the Fund for Scientific Research - Flanders (FWO-Vlaanderen).

\section{References}

1 Parkin DM, Bray F, Ferlay J, Pisani P. Global cancer statistics, 2002. CA Cancer J Clin 2005; 55: 74-108.

2 El-Serag HB, Mason AC. Rising incidence of hepatocellular carcinoma in the United States. N Engl J Med 1999; 340: 745-50. 
3 Guyot C, Lepreux S, Combe C, Doudnikoff E, Bioulac-Sage P, Balabaud C, et al. Hepatic fibrosis and cirrhosis: the (myo)fibroblastic cell subpopulations involved. Int J Biochem Cell Biol 2006; 38: 13551.

4 Sangiovanni A, Del Ninno E, Fasani P, De Fazio C, Ronchi G, Romeo $\mathrm{R}$, et al. Increased survival of cirrhotic patients with a hepatocellular carcinoma detected during surveillance. Gastroenterology 2004; 126: 1005-14.

5 Llovet JM, Burroughs A, Bruix J. Hepatocellular carcinoma. Lancet 2003; 362: 1907-17.

6 Bosch FX, Ribes J, Díaz M, Cléries R. Primary liver cancer: worldwide incidence and trends. Gastroenterology 2004; 127(5 Suppl 1): S5S16.

7 Bissell DM, Gores GJ, Laskin DL, Hoofnagle JH. Drug-induced liver injury: mechanisms and test systems. Hepatology 2001; 33: 100913.

8 Herzer K, Sprinzl MF, Galle PR. Hepatitis viruses: live and let die. Liver Int 2007; 27: 293-301.

9 Severi T, Vander Borght S, Libbrecht L, VanAelst L, Nevens F, Roskams T, et al. HBx or HCV core gene expression in HepG2 human liver cells results in a survival benefit against oxidative stress with possible implications for HCC development. Chem Biol Interact 2007; 168: 128-34.

10 Ramadori G, Saile B. Inflammation, damage repair, immune cells, and liver fibrosis: specific or nonspecific, this is the question. Gastroenterology 2004; 127: 997-1000.

11 Ramadori G, Saile B. Portal tract fibrogenesis in the liver. Lab Invest 2004; 84: 153-9.

12 De Giorgio M, Fagiuoli S. Management of hepatocellular carcinoma. Dig Dis 2007; 25: 279-81.

13 Kojiro M, Roskams T. Early hepatocellular carcinoma and dysplastic nodules. Semin Liver Dis 2005; 25: 133-42.

14 Roskams TA, Libbrecht L, Desmet VJ. Progenitor cells in diseased human liver. Semin Liver Dis 2003; 23: 385-96.

15 Pineau P, Marchio A, Battiston C, Cordina E, Russo A, Terris B, et al. Chromosome instability in human hepatocellular carcinoma depends on p53 status and aflatoxin exposure. Mutat Res 2008; 653: 6-13.

16 El-Serag HB, Rudolph KL. Hepatocellular carcinoma: epidemiology and molecular carcinogenesis. Gastroenterology 2007; 132: 255776.

17 Brechot C. Pathogenesis of hepatitis B virus-related hepatocellular carcinoma: old and new paradigms. Gastroenterology 2004; 127(5 Suppl 1): S56-61.

18 Lupberger J, Hildt E. Hepatitis B virus-induced oncogenesis. World J Gastroenterol 2007; 13: 74-81.

19 Dryden KA, Wieland SF, Whitten-Bauer C, Gerin JL, Chisari FV, Yeager $M$. Native hepatitis $B$ virions and capsids visualized by electron cryomicroscopy. Mol Cell 2006; 22: 843-50.

20 Chisari FV, Ferrari C. Hepatitis B virus immunopathology. Springer Semin Immunopathol 1995; 17: 261-81.

21 Chen X, Cheung ST, So S, Fan ST, Barry C, Higgins J, et al. Gene expression patterns in human liver cancers. Mol Biol Cell 2002; 13: 1929-39.

22 Lara-Pezzi E, Gómez-Gaviro MV, Gálvez BG, Mira E, Iñiguez MA, Fresno $\mathrm{M}$, et al. The hepatitis $\mathrm{B}$ virus $\mathrm{X}$ protein promotes tumour cell invasion by inducing membrane-type matrix metalloproteinase- 1 and cyclooxygenase-2 expression. J Clin Invest 2002; 110: 1831-8.

23 Yun C, Um HR, Jin YH, Wang JH, Lee MO, Park S, et al. NF-kappaB activation by hepatitis $B$ virus $X(\mathrm{HBx})$ protein shifts the cellular fate toward survival. Cancer Lett 2002; 184: 97-104.

24 Billerbeck E, Bottler T, Thimme R. Regulatory T cells in viral hepatitis.
World J Gastroenterol 2007; 13: 4858-64.

25 Fattovich G, Llovet JM. Risk factors for hepatocellular carcinoma in HCV-cirrhosis: what we know and what is missing. J Hepatol 2006;. 44: 1013-6.

26 Seitz HK, Stickel F. Risk factors and mechanisms of hepatocarcinogenesis with special emphasis on alcohol and oxidative stress. Biol Chem 2006; 387: 349-60.

27 Murakami Y, Saigo K, Takashima H, Minami M, Okanoue T, Bréchot C, et al. Large scaled analysis of hepatitis B virus (HBV) DNA integration in HBV related hepatocellular carcinomas. Gut 2005; 54: 1162-8.

28 Levrero M, Pollicino T, Petersen J, Belloni L, Raimondo G, Dandri M. Control of cccDNA function in hepatitis $B$ virus infection. J Hepatol 2009; 51: 581-92.

29 De Mitri MS, Cassini R, Bernardi M. Hepatitis B virus-related hepatocarcinogenesis: Molecular oncogenic potential of clear or occult infections. Eur J Cancer 2010; 46: 2178-86.

30 Huo TI, Wang XW, Forgues M, Wu CG, Spillare EA, Giannini C, et al. Hepatitis $B$ virus $X$ mutants derived from human hepatocellular carcinoma retain the ability to abrogate p53-induced apoptosis. Oncogene 2001; 20: 3620-8.

31 Benhenda S, Cougot D, Buendia MA, Neuveut C. Hepatitis B virus $X$ protein molecular functions and its role in virus life cycle and pathogenesis. Adv Cancer Res 2009; 103: 75-109.

32 Kim CM, Koike K, Saito I, Miyamura T, Jay G. HBx gene of hepatitis $B$ virus induces liver cancer in transgenic mice. Nature 1991; 351: 317-20.

$33 \mathrm{Kim} \mathrm{K,} \mathrm{Kim} \mathrm{KH,} \mathrm{Cheong} \mathrm{J.} \mathrm{Hepatitis} \mathrm{B} \mathrm{virus} \mathrm{X} \mathrm{protein} \mathrm{impairs} \mathrm{hepatic}$ insulin signaling through degradation of IRS1 and induction of SOCS3. PLoS One 2010; 5: e8649.

34 Luan F, Liu H, Gao L, Liu J, Sun Z, Ju Y, et al. Hepatitis B virus protein preS2 potentially promotes HCC development via its transcriptional activation of hTERT. Gut 2009; 58: 1528-37.

35 Idilman R, De Maria N, Colantoni A, Van Thiel DH. Pathogenesis of hepatitis B and C-induced hepatocellular carcinoma. J Viral Hepat 1998; 5: 285-99.

36 Rehermann B, Nascimbeni M. Immunology of hepatitis B virus and hepatitis C virus infection. Nat Rev Immunol. 2005; 5: 215-29.

37 Suzuki T, Aizaki H, Murakami K, Shoji I, Wakita T. Molecular biology of hepatitis C virus. J Gastroenterol 2007; 42: 411-23.

38 Majumder M, Ghosh AK, Steele R, Zhou XY, Phillips NJ, Ray R, et al. Hepatitis $C$ virus NS5A protein impairs TNF-mediated hepatic apoptosis, but not by an anti-FAS antibody, in transgenic mice. Virology 2002; 294: 94-105.

39 Calle EE, Rodriguez C, Walker-Thurmond K, Thun MJ. Overweight, obesity, and mortality from cancer in a prospectively studied cohort of US adults. N Engl J Med 2003; 348: 1625-38.

40 Decock S, Verslype C, Fevery J. Hepatitis $C$ and insulin resistance: mutual interactions. Acta Clin Belg 2007; 62: 111-9.

41 Battaglia S, Benzoubir N, Nobilet S, Charneau P, Samuel D, Zignego AL, et al. Liver cancer-derived hepatitis $C$ virus core proteins shift TGFbeta responses from tumor suppression to epithelial-mesenchymal transition. PLoS One 2009; 4: e4355.

42 Fishman SL, Factor SH, Balestrieri C, Fan X, Dibisceglie AM, Desai $\mathrm{SM}$, et al. Mutations in the hepatitis $C$ virus core gene are associated with advanced liver disease and hepatocellular carcinoma. Clin Cancer Res 2009; 15: 3205-13.

43 Nakamoto S, Imazeki F, Fukai K, Fujiwara K, Arai M, Kanda T, et al. Association between mutations in the core region of hepatitis $C$ virus genotype 1 and hepatocellular carcinoma development. J Hepatol 2010; 52: 72-8.

44 Wang AG, Lee DS, Moon HB, Kim JM, Cho KH, Choi SH, et al. Non- 
structural $5 \mathrm{~A}$ protein of hepatitis $\mathrm{C}$ virus induces a range of liver pathology in transgenic mice. J Pathol 2009; 219: 253-62.

45 Milward A, Mankouri J, Harris M. Hepatitis C virus NS5A protein interacts with beta-catenin and stimulates its transcriptional activity in a phosphoinositide-3 kinase-dependent fashion. J Gen Virol 2010; 91: 373-81.

46 Hernandez-Vargas H, Lambert MP, Le Calvez-Kelm F, Gouysse G, McKay-Chopin S, Tavtigian SV, et al. Hepatocellular carcinoma displays distinct DNA methylation signatures with potential as clinical predictors. PLoS One 2010; 5: e9749.

47 Deng YB, Nagae G, Midorikawa Y, Yagi K, Tsutsumi S, Yamamoto S, et al. Identification of genes preferentially methylated in hepatitis C virus-related hepatocellular carcinoma. Cancer Sci 2010; 101: 1501-10.

48 Cassiman D, Jaeken J. NASH may be trash. Gut 2008; 57: 141-4.

49 Brunt EM. Histopathology of non-alcoholic fatty liver disease. Clin Liver Dis 2009; 13: 533-44.

50 Guzman G, Brunt EM, Petrovic LM, Chejfec G, Layden TJ, Cotler SJ. Does nonalcoholic fatty liver disease predispose patients to hepatocellular carcinoma in the absence of cirrhosis? Arch Pathol Lab Med 2008; 132: 1761-6.

51 Ascha MS, Hanouneh IA, Lopez R, Tamimi TA, Feldstein AF, Zein NN. The incidence and risk factors of hepatocellular carcinoma in patients with nonalcoholic steatohepatitis. Hepatology 2010; 51: 1972-8.

52 Siegel AB, Zhu AX. Metabolic syndrome and hepatocellular carcinoma: two growing epidemics with a potential link. Cancer 2009; 115: 5651-61

53 Hashimoto E, Yatsuji S, Tobari M, Taniai M, Torii N, Tokushige K, Shiratori K. Hepatocellular carcinoma in patients with nonalcoholic steatohepatitis. J Gastroenterol 2009; 44 (Suppl 19): 89-95

54 Jou J, Choi SS, Diehl AM. Mechanisms of disease progression in nonalcoholic fatty liver disease. Semin Liver Dis 2008; 28: 370-9.

55 McKillop IH, Schrum LW. Role of alcohol in liver carcinogenesis. Semin Liver Dis 2009; 29: 222-32.

56 Shukla SD, Aroor AR. Epigenetic effects of ethanol on liver and gastrointestinal injury. World J Gastroenterol 2006; 12: 5265-71.

57 Barron AM, Fuller SJ, Verdile G, Martins RN. Reproductive hormones modulate oxidative stress in Alzheimer's disease. Antioxid Redox Signal 2006; 8: 2047-59.

58 Reynolds A, Laurie C, Mosley RL, Gendelman HE. Oxidative stress and the pathogenesis of neurodegenerative disorders. Int Rev Neurobiol 2007; 82: 297-325.

59 Okuda M, Li K, Beard MR, Showalter LA, Scholle F, Lemon SM, et al. Mitochondrial injury, oxidative stress, and antioxidant gene expression are induced by hepatitis $\mathrm{C}$ virus core protein. Gastroenterology 2002; 122: 366-75.

60 Nakamura H, Nakamura K, Yodoi J. Redox regulation of cellular activation. Annu Rev Immunol 1997; 15: 351-69.

61 Nkabyo YS, Ziegler TR, Gu LH, Watson WH, Jones DP. Glutathione and thioredoxin redox during differentiation in human colon epithelial (Caco-2) cells. Am J Physiol Gastrointest Liver Physiol 2002; 283: G1352-9.

62 Nagoev BS, Abidov MT, Ivanova MR. LPO and free-radical oxidation parameters in patients with acute viral hepatitis. Bull Exp Biol Med 2002; 134: 557-8.

63 Filomeni G, Rotilio G, Ciriolo MR. Glutathione disulfide induces apoptosis in $U 937$ cells by a redox-mediated p38 MAP kinase pathway. Faseb J 2003; 17: 64-6.

64 Shimoda R, Nagashima M, Sakamoto M, Yamaguchi N, Hirohashi $\mathrm{S}$, Yokota J, et al. Increased formation of oxidative DNA damage, 8-hydroxydeoxyguanosine, in human livers with chronic hepatitis. Cancer Res 1994; 54: 3171-2.

65 Dandri M, Burda MR, Bürkle A, Zuckerman DM, Will H, Rogler $\mathrm{CE}$, et al. Increase in de novo HBV DNA integrations in response to oxidative DNA damage or inhibition of poly(ADP-ribosyl)ation. Hepatology 2002; 35: 217-23.

66 Rabe C, Cheng B, Caselmann WH. Molecular mechanisms of hepatitis B virus-associated liver cancer. Dig Dis 2001; 19: 279-87.

67 Hussain SM, Zondervan PE, IJzermans JN, Schalm SW, de Man RA, Krestin GP. et al. Benign versus malignant hepatic nodules: MR imaging findings with pathologic correlation. Radiographics 2002; 22: $1023-36$

68 Wang XW, Hussain SP, Huo TI, Wu CG, Forgues M, Hofseth LJ, et al. Molecular pathogenesis of human hepatocellular carcinoma. Toxicology 2002; 181-182: 43-7.

69 Oliva J, French BA, Qing X, French SW. The identification of stem cells in human liver diseases and hepatocellular carcinoma. Exp Mol Pathol 2010; 88: 331-40.

70 Lee JS, Heo J, Libbrecht L, Chu IS, Kaposi-Novak P, Calvisi DF, et al. A novel prognostic subtype of human hepatocellular carcinoma derived from hepatic progenitor cells. Nat Med 2006; 12: 410-41.

71 Spee B, Carpino G, Schotanus BA, Katoonizadeh A, Vander Borght S, Gaudio $E$, et al. Characterisation of the activated liver progenitor cell niche, potential involvement of Wnt and Notch signalling. Gut 2010; 59: $247-57$.

72 Durnez A, Verslype C, Nevens F, Fevery J, Aerts R, Pirenne J, et al. The clinicopathological and prognostic relevance of cytokeratin 7 and 19 expression in hepatocellular carcinoma. A possible progenitor cell origin. Histopathology 2006; 49: 138-51.

73 Uenishi T, Kubo S, Yamamoto T, Shuto T, Ogawa M, Tanaka H, et al. Cytokeratin 19 expression in hepatocellular carcinoma predicts early postoperative recurrence. Cancer Sci 2003; 94: 851-7.

74 Yang XR, Xu Y, Shi GM, Fan J, Zhou J, Ji Y, et al. Cytokeratin 10 and cytokeratin 19: predictive markers for poor prognosis in hepatocellular carcinoma patients after curative resection. Clin Cancer Res 2008; 14: 3850-9.

75 Yamashita T, Forgues M, Wang W, Kim JW, Ye Q, Jia H, et al. EpCAM and alpha-fetoprotein expression defines novel prognostic subtypes of hepatocellular carcinoma. Cancer Res 2008; 68: 1451-61.

76 Witz IP. The tumor microenvironment: the making of a paradigm. Cancer Microenviron 2009; 2: 9-17.

77 Mantovani A, Allavena P, Sica A, Balkwill F. Cancer-related inflammation. Nature 2008 ; 454: 436-44.

78 Kalluri R, Zeisberg M. Fibroblasts in cancer. Nat Rev Cancer 2006; 6: 392-401.

79 Mazzocca A, Fransvea E, Dituri F, Lupo L, Antonaci S, Giannelli G. Down-regulation of connective tissue growth factor by inhibition of transforming growth factor beta blocks the tumor-stroma cross-talk and tumor progression in hepatocellular carcinoma. Hepatology 2010; 51: 523-34.

80 van Zijl F, Mair M, Csiszar A, Schneller D, Zulehner G, Huber H, et al. Hepatic tumor-stroma crosstalk guides epithelial to mesenchymal transition at the tumor edge. Oncogene 2009; 28: 4022-33.

81 Sasaki K, Natsugoe S, Ishigami S, Matsumoto M, Okumura H, Setoyama T, et al. Significance of Twist expression and its association with E-cadherin in esophageal squamous cell carcinoma. J Exp Clin Cancer Res 2009; 28: 158.

82 Iwatsuki M, Mimori K, Fukagawa T, Ishii H, Yokobori T, Sasako M, et al. The Clinical Significance of Vimentin-Expressing Gastric Cancer Cells in Bone Marrow. Ann Surg Oncol 2010; 17: 2526-33.

83 Jäger T, Becker M, Eisenhardt A, Tilki D, Tötsch M, Schmid KW, et al. 
The prognostic value of cadherin switch in bladder cancer. Oncol Rep 2010; 23: 1125-32.

84 Soltermann A, Tischler V, Arbogast S, Braun J, Probst-Hensch N, Weder W, et al. Prognostic significance of epithelial-mesenchymal and mesenchymal-epithelial transition protein expression in nonsmall cell lung cancer. Clin Cancer Res 2008; 14: 7430-7.

85 Cates JM, Byrd RH, Fohn LE, Tatsas AD, Washington MK, Black CC. Epithelial-mesenchymal transition markers in pancreatic ductal adenocarcinoma. Pancreas 2009; 38: e1-6.

86 Yang MH, Chen CL, Chau GY, Chiou SH, Su CW, Chou TY, et al. Comprehensive analysis of the independent effect of twist and snail in promoting metastasis of hepatocellular carcinoma. Hepatology 2009; 50: 1464-74.

87 Niu RF, Zhang L, Xi GM, Wei XY, Yang Y, Shi YR, Hao XS. Up-regulation of Twist induces angiogenesis and correlates with metastasis in hepatocellular carcinoma. J Exp Clin Cancer Res 2007; 26: 385-94.

88 Chen L, Chan TH, Yuan YF, Hu L, Huang J, Ma S, et al. CHD1L promotes hepatocellular carcinoma progression and metastasis in mice and is associated with these processes in human patients. J Clin Invest 2010; 120: 1178-91.

89 van Zijl F, Zulehner G, Petz M, Schneller D, Kornauth C, Hau M, et al. Epithelial-mesenchymal transition in hepatocellular carcinoma. Future Oncol 2009; 5: 1169-79.

90 Lee TK, Poon RT, Yuen AP, Ling MT, Kwok WK, Wang XH, et al. Twist overexpression correlates with hepatocellular carcinoma metastasis through induction of epithelial-mesenchymal transition. Clin Cancer Res 2006; 12: 5369-76.

91 Cicchini C, Laudadio I, Citarella F, Corazzari M, Steindler C, Conigliaro $A$, et al. TGFbeta-induced EMT requires focal adhesion kinase (FAK) signaling. Exp Cell Res 2008; 314: 143-52.

92 Matsuo N, Shiraha H, Fujikawa T, Takaoka N, Ueda N, Tanaka S, et al. Twist expression promotes migration and invasion in hepatocellular carcinoma. BMC Cancer 2009; 9: 240.

93 Kokkinos MI, Wafai R, Wong MK, Newgreen DF, Thompson EW, Waltham M. Vimentin and epithelial-mesenchymal transition in human breast cancer-observations in vitro and in vivo. Cells Tissues Organs 2007; 185: 191-203

94 Zeisberg M, Neilson EG. Biomarkers for epithelial-mesenchymal transitions J Clin Invest 2009; 119: 1429-37.

95 van Zijl F, Zulehner G, Petz M, Schneller D, Kornauth C, Hau M, et al. Epithelial-mesenchymal transition in hepatocellular carcinoma. Future Oncol 2009; 5: 1169-79.

96 Venkov CD, Link AJ, Jennings JL, Plieth D, Inoue T, Nagai K, et al. A proximal activator of transcription in epithelial-mesenchymal transition. J Clin Invest 2007; 117: 482-91.

97 Gotzmann J, Fischer AN, Zojer M, Mikula M, Proell V, Huber H, et al. A crucial function of PDGF in TGF-beta-mediated cancer progression of hepatocytes. Oncogene 2006; 25: 3170-85.

98 Lin CY, Lin CJ, Chen KH, Wu JC, Huang SH, Wang SM. Macrophage activation increases the invasive properties of hepatoma cells by destabilization of the adherens junction. FEBS Lett 2006; 580: 3042-50.

99 Ding W, You H, Dang H, Leblanc F, Galicia V, Lu SC, et al. Epithelialto-mesenchymal transition of murine liver tumor cells promotes invasion. Hepatology 2010; 52: 945-53.

100 Chen L, Chan TH, Yuan YF, Hu L, Huang J, Ma S, et al. CHD1L promotes hepatocellular carcinoma progression and metastasis in mice and is associated with these processes in human patients. J Clin Invest 2010; 120: 1178-91.

101 Yang SZ, Zhang LD, Zhang Y, Xiong Y, Zhang YJ, Li HL, et al. HBx protein induces EMT through c-Src activation in SMMC-7721 hepa- toma cell line. Biochem Biophys Res Commun 2009; 382: 555-60.

102 Battaglia S, Benzoubir N, Nobilet S, Charneau P, Samuel D, Zignego $\mathrm{AL}$, et al. Liver cancer-derived hepatitis $\mathrm{C}$ virus core proteins shift TGFbeta responses from tumor suppression to epithelial-mesenchymal transition. PLoS One 2009; 4: e4355.

103 Dayan F, Mazure NM, Brahimi-Horn MC, Pouysségur J. A Dialogue between the Hypoxia-Inducible Factor and the Tumor Microenvironment Cancer Microenviron 2008; 1: 53-68.

104 Copple BL. Hypoxia stimulates hepatocyte epithelial to mesenchymal transition by hypoxia-inducible factor and transforming growth factorbeta-dependent mechanisms. Liver Int 2010; 30: 669-82.

105 Kim J, Hong SJ, Park JY, Park JH, Yu YS, Park SY, et al. Epithelialmesenchymal transition gene signature to predict clinical outcome of hepatocellular carcinoma. Cancer Sci 2010; 101: 1521-8.

106 Villanueva A, Newell P, Chiang DY, Friedman SL, Llovet JM. Genomics and signaling pathways in hepatocellular carcinoma. Semin Liver Dis 2007; 27: 55-76.

107 Boyault S, Rickman DS, de Reyniès A, Balabaud C, Rebouissou S, Jeannot E, et al. Transcriptome classification of HCC is related to gene alterations and to new therapeutic targets. Hepatology 2007; 45: 42-52.

108 Chiang DY, Villanueva A, Hoshida Y, Peix J, Newell P, Minguez B, et al. Focal gains of VEGFA and molecular classification of hepatocellular carcinoma. Cancer Res 2008; 68: 6779-88.

109 Lee JS, Chu IS, Heo J, Calvisi DF, Sun Z, Roskams T, et al. Classification and prediction of survival in hepatocellular carcinoma by gene expression profiling. Hepatology 2004; 40: 667-76.

110 Wurmbach E, Chen YB, Khitrov G, Zhang W, Roayaie S, Schwartz M, et al. Genome-wide molecular profiles of HCV-induced dysplasia and hepatocellular carcinoma. Hepatology 2007; 45: 938-47.

111 Breuhahn K, Schirmacher P. Reactivation of the insulin-like growth factor-II signaling pathway in human hepatocellular carcinoma. World J Gastroenterol 2008; 14: 1690-8.

112 lizuka N, Tamesa T, Sakamoto K, Miyamoto T, Hamamoto Y, Oka M. Different molecular pathways determining extrahepatic and intrahepatic recurrences of hepatocellular carcinoma. Oncol Rep 2006; 16: 1137-42.

113 Woo HG, Park ES, Cheon JH, Kim JH, Lee JS, Park BJ, et al. Gene expression-based recurrence prediction of hepatitis $\mathrm{B}$ virus-related human hepatocellular carcinoma. Clin Cancer Res 2008; 14: 205664.

114 Ye QH, Qin LX, Forgues M, He P, Kim JW, Peng AC, et al. Predicting hepatitis $B$ virus-positive metastatic hepatocellular carcinomas using gene expression profiling and supervised machine learning. Nat Med 2003; 9: 416-23.

115 Chen XY, Li JS, Ma J, Duan FL, Zhong P. Potential role of novel hepatocellular carcinoma-associated gene IDD01 in promoting tumourigenesis of HepG2 cell line. Chin Med J (Engl) 2006; 119: 1709-14.

116 Okabe H, Furukawa Y, Kato T, Hasegawa S, Yamaoka Y, Nakamura Y. Isolation of development and differentiation enhancing factor-like 1 (DDEFL1) as a drug target for hepatocellular carcinomas. Int J Oncol 2004; 24: 43-8.

117 Hoshida Y, Nijman SM, Kobayashi M, Chan JA, Brunet JP, Chiang DY, et al. Integrative transcriptome analysis reveals common molecular subclasses of human hepatocellular carcinoma. Cancer Res 2009; 69: 7385-92.

118 Budhu A, Forgues M, Ye QH, Jia HL, He P, Zanetti KA, et al. Prediction of venous metastases, recurrence, and prognosis in hepatocellular carcinoma based on a unique immune response signature of the liver microenvironment. Cancer Cell 2006; 10: 99-111.

119 Dufour J-F, Johnson P. Liver cancer: From molecular pathogenesis 
to new therapies. Summary of the EASL single topic conference. J Hepatol 2010; 52: 296-304

120 Murata K, Suzuki H, Okano H, Oyamada T, Yasuda Y, Sakamoto A. Hypoxia-induced des-gamma-carboxy prothrombin production in hepatocellular carcinoma. Int J Oncol 2010; 36: 161-70.

121 Yan W, Fu Y, Tian D, Liao J, Liu M, Wang B, et al. PI3 kinase/Akt signaling mediates epithelial-mesenchymal transition in hypoxic hepatocellular carcinoma cells. Biochem Biophys Res Commun. 2009; 382: 631-6.

122 Haase VH. Oxygen regulates epithelial-to-mesenchymal transition: insights into molecular mechanisms and relevance to disease. Kidney Int 2009; 76: 492-49.

123 Sun S, Ning X, Zhang Y, Lu Y, Nie Y, Han S, et al. Hypoxia-inducible factor-1alpha induces Twist expression in tubular epithelial cells subjected to hypoxia, leading to epithelial-to-mesenchymal transition. Kidney Int 2009; 75: 1278-87.

124 van Malenstein H, Gevaert O, Libbrecht L, Daemen A, Allemeersch J, Nevens F, et al. A 7 Gene Set Associated with Chronic Hypoxia of Prognostic Importance in Hepatocellular Carcinoma. Clin Cancer Res 2010; 16: 4278-88.

125 Hoshida Y, Toffanin S, Lachenmayer A, Villanueva A, Minguez B,
Llovet JM. Molecular classification and novel targets in hepatocellular carcinoma: recent advancements. Semin Liver Dis 2010; 30: 35-51. 126 http://clinicaltrials.gov

127 Bruix J, Sherman M; Practice Guidelines Committee, American Association for the Study of Liver Diseases. Management of hepatocellular carcinoma. Hepatology 2005; 42: 1208-36.

128 Llovet JM, Di Bisceglie AM, Bruix J, Kramer BS, Lencioni R, Zhu $A X$, et al. Design and endpoints of clinical trials in hepatocellular carcinoma. J Natl Cancer Inst 2008; 100: 698-711.

129 Verslype C, Van Cutsem E, Dicato M, Arber N, Berlin JD, Cunningham D, et al. The management of hepatocellular carcinoma. Current expert opinion and recommendations derived from the 10th World Congress on Gastrointestinal Cancer, Barcelona, 2008. Ann Oncol 2009; 20 (Suppl 7): vii1-vii6.

130 Llovet JM, Ricci S, Mazzaferro V, Hilgard P, Gane E, Blanc JF, et al. Sorafenib in advanced hepatocellular carcinoma. N Engl J Med 2008; 359: 378-90

131 Cheng AL, Kang YK, Chen Z, Tsao CJ, Qin S, Kim JS, et al. Efficacy and safety of sorafenib in patients in the Asia-Pacific region with advanced hepatocellular carcinoma: a phase III randomised, doubleblind, placebo-controlled trial. Lancet Oncol 2009; 10: 25-34. 